\title{
Brucellosis As a Cause of Intestinal Perforation
}

\author{
Iffat Noureen ${ }^{1}$, Muhammad Hamza ${ }^{2}$, Huma Sabir Khan ${ }^{1}$, Saleha Khan ${ }^{1}$, Muhammad Hanif ${ }^{3}$ \\ 1. Surgical Unit II, Benazir Bhutto Hospital, Rawalpindi Medical University, Rawalpindi, PAK 2. Surgery Unit II, Benazir \\ Bhutto Hospital, Rawalpindi Medical University, Rawalpindi, PAK 3. Surgical Unit II, Benazir Bhutto Hospital, \\ Rawalpindi Medical Uninversity, Rawalpindi, PAK
}

Corresponding author: Muhammad Hamza, mhamza7593@gmail.com

\begin{abstract}
Brucellosis is a multisystem zoonotic infection. Patients usually presents with fever and nonspecific systemic symptoms but may rarely present with clinical presentation of an acute abdomen. In this case report, we present a 32-year-old male who presented to the emergency department with symptoms of acute abdomen. Exploration revealed ileal perforation secondary to brucellosis, for which loop ileostomy was fashioned.
\end{abstract}

Categories: Pathology, General Surgery, Infectious Disease

Keywords: brucellosis, acute abdomen, intestinal perforation, appendicitis, ileostomy, ileitis

\section{Introduction}

Brucellosis is a zoonotic infection caused by facultative intracellular bacteria of the genus Brucella, which can involve multiple tissues and organs [1]. It is transmitted to humans from infected animals (cattle, sheep, goats, camels, pigs, or other animals) by ingestion of unpasteurized dairy products or by contact with infected fluids and tissues. It is a systemic infection with versatile presentations and systemic complications, among which gastrointestinal complications are very rare. This report presents a rare case of a young male patient who presented with peritonitis/acute abdomen caused by ileal perforation due to brucellosis.

\section{Case Presentation}

A 32-year-old, unmarried, nonsmoker male presented to the emergency department with generalized abdominal pain more marked in the right lower abdomen for one day. He had a history of high-grade fever associated with rigors and chills for 10 days. Fever was temporarily relieved by local antipyretics. He was otherwise fine with no history of nausea, vomiting, diarrhea, and constipation. He had no history of any urinary or genital symptoms. He had a history of consuming unpasteurized milk but had no history of animal contact. He was a shopkeeper by profession. He had no history of any medical illness, allergy, or surgery. There was no significant family or psychosocial history.

Received 02/03/2020 Review began 02/15/2020 Review ended 02/19/2020 Published 02/22/2020

\section{() Copyright 2020}

Noureen et al. This is an open access article distributed under the terms of the Creative Commons Attribution License CC-BY 4.0., which permits unrestricted use, distribution, and reproduction in any medium, provided the original author and source are credited.
At presentation to the hospital, he had a pulse of 110 per minute, a blood pressure of $100 / 60 \mathrm{mmHg}$, a respiratory rate of 26 per minute, a temperature of $99^{\circ} \mathrm{F}$, an oxygen saturation of $99 \%$ on room air, and random blood sugar of $105 \mathrm{mg} / \mathrm{dl}$. The patient had an ill-look with pallor. The abdomen was generalized tender more in the right iliac fossa with guarding and rebound tenderness. Bowel sounds were absent. Psoas sign and obturator sign of acute appendicitis were positive. The rest of the systemic examination was unremarkable.

\section{Lab investigations revealed that hemoglobin was $13 \mathrm{~g} / \mathrm{dl}$, total leukocyte count was $13,200 / \mathrm{mm}^{3}$} (neutrophilia), and platelet count was $338,000 / \mathrm{mm}^{3}$. Liver function tests, renal function tests, serum electrolytes, partial thromboplastin time (PTT), and activated PTT were normal. Hepatitis B and C profiles were negative. Ultrasound showed coarse liver with irregular margin, splenomegaly, and mild free fluid in the right iliac fossa with decreased intestinal peristaltic activity. Chest x-ray and abdominal x-ray had insignificant findings.

Based on this history, clinical examination, and investigation, diagnosis of acute appendicitis was established. The patient was prepared for open appendectomy in the emergency department of Rawalpindi Hospital, Pakistan. The patient and his attendants were counseled and informed consent was taken. The patient was explored using Gird-iron incision which was later extended to Rutherford incision. The operative finding was a single pinpoint perforation in ileum which was $12 \mathrm{~cm}$ from the ileocecal junction with minimal intra-abdominal contamination for which loop ileostomy was fashioned after washing the abdomen with adequate (5 1) normal saline. The rest of the bowel and viscera were normal. No drain was placed. The patient was admitted to the in-patient facility of the hospital.

During the patient stay in the hospital, the fever of the patient did not settle despite giving postoperative antibiotics like ceftriaxone $1 \mathrm{~g}$ IV BD, metronidazole $500 \mathrm{mg}$ IV TDS, and azithromycin $500 \mathrm{mg}$ IV BD. Urine $\mathrm{R} / \mathrm{E}$ was insignificant, and urine culture was negative. The Typhidot IgM and IgG were negative. Malarial 


\section{Cureus}

parasite thick and thin smears were negative.

After eight days of the first surgery, he developed fecal peritonitis for which re-exploration was done through a midline incision. A pinpoint perforation was seen in proximal ileum. There was extensive ileitis. A limited right hemicolectomy and ileocolostomy were done.

Despite the second exploration, his fever did not settle. Brucella IgG and IgM antibodies were measured by enzyme-linked immunosorbent assay (ELISA), which surprisingly came out to be reactive (positive). Brucella IgG was 2.43 (reference value was 0.9-1.1) and Brucella IgM was 1.89 (reference value was 0.9-1.1). Brucella antigen titer for Brucella abortus was 1:160 (positive) and Brucella antigen titre for Brucella mellitensis was 1:160 (positive). The blood culture report showed no growth. The patient was given tablet doxycycline 100 mg BD for six weeks, tablet rifampicin $600 \mathrm{mg}$ OD for six weeks, tablet metronidazole $400 \mathrm{mg}$ TDS for seven days, and tablet acetaminophen for fever. After taking these antibiotics, the patient started to improve. Histopathology report showed that the ileum section of perforation had surface ulceration, transmural inflammation, hemorrhages, suppuration, focal fibrosis, and congested blood vessels. The outer serosal surface had inflamed fibrinous exudate (Figures 1,2).

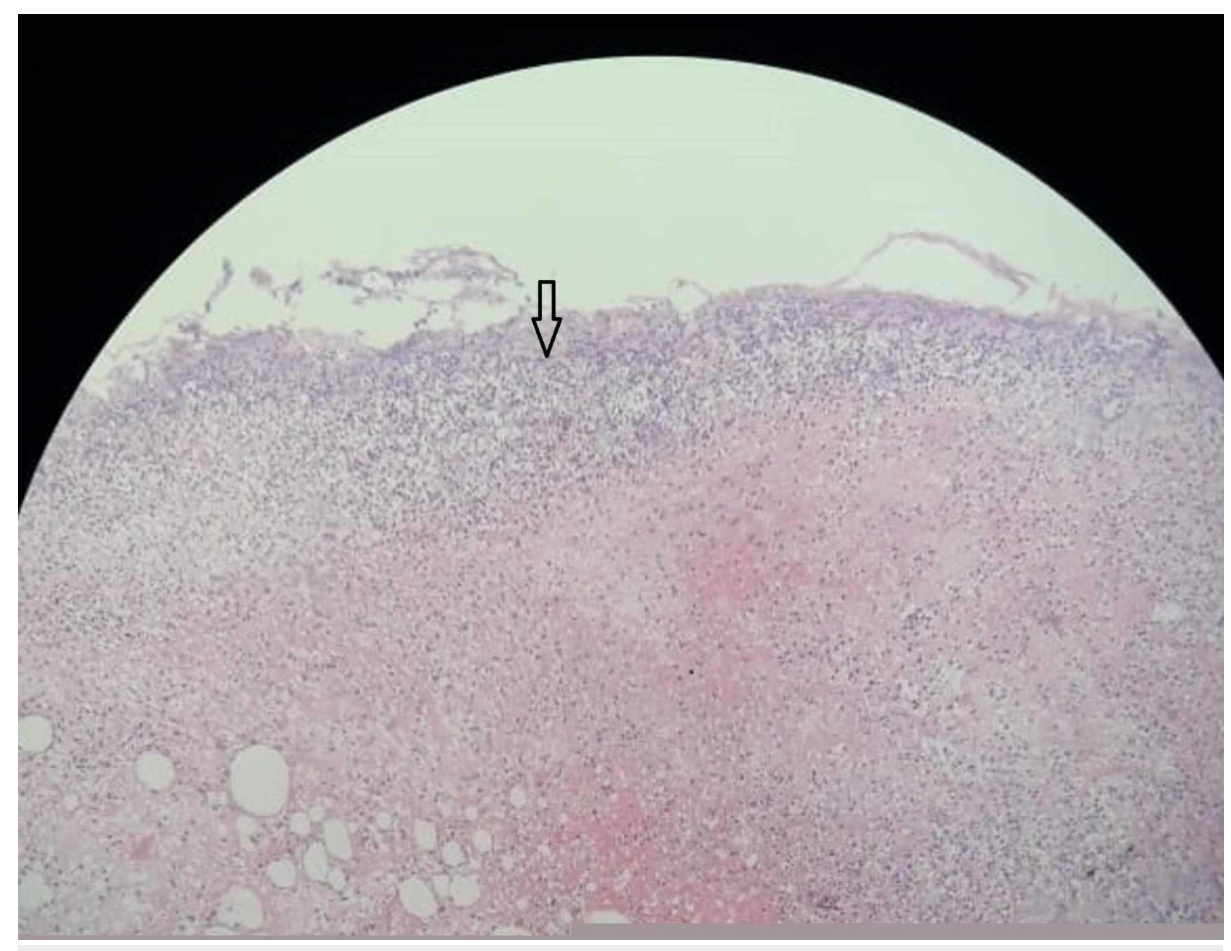

FIGURE 1: Photomicrograph (H\&E, x10) shows section of perforation of ileum with neutrophilic infiltrates (pointer arrow) and areas of hemorrhage. 


\section{Cureus}

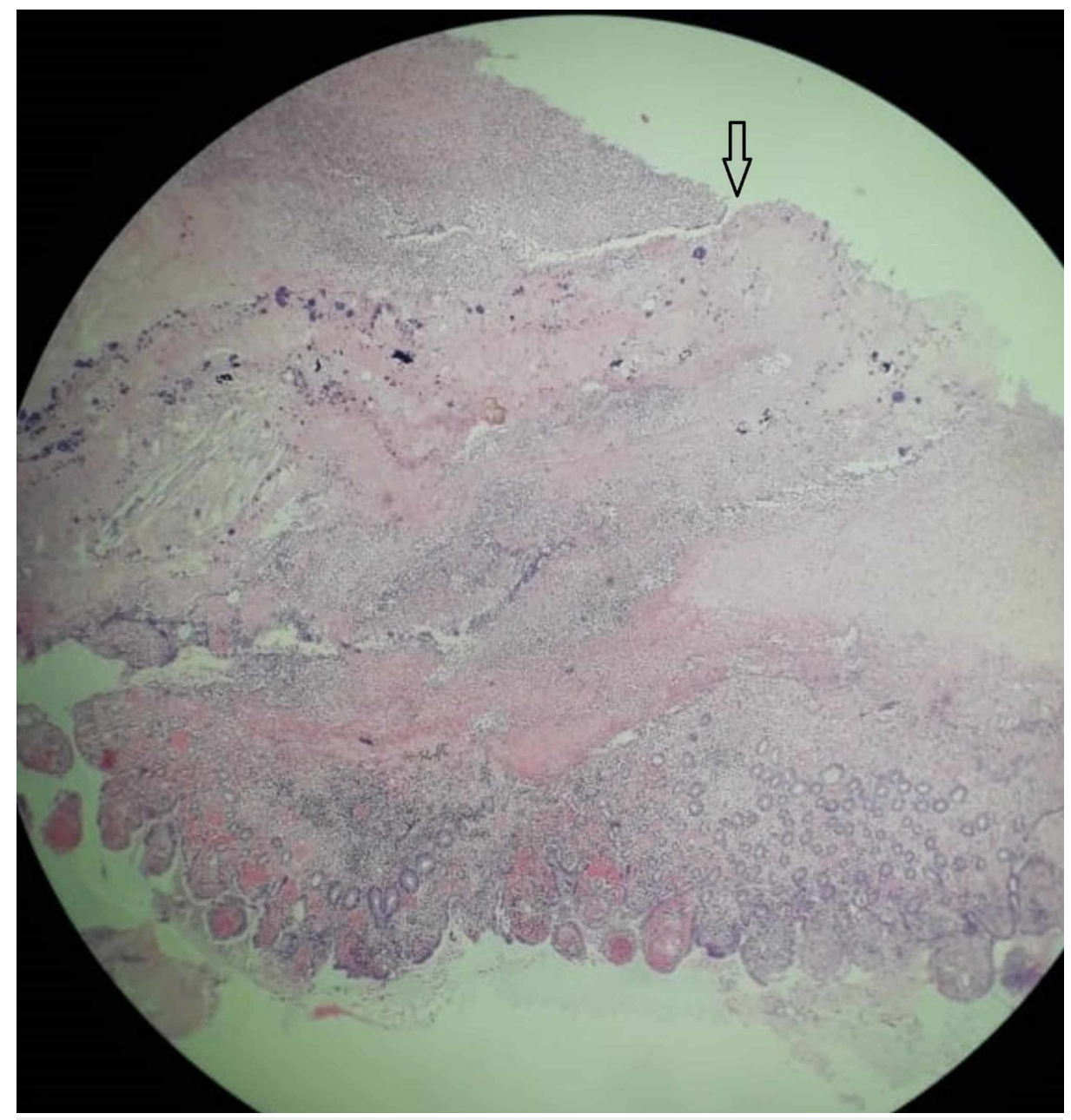

FIGURE 2: Photomicrograph (H\&E, x40) shows segment of perforation of ileum with focal surface ulceration (arrow), suppuration, transmural inflammation, and congested blood vessels.

The section of the terminal ileum had lymphoid hyperplasia of Peyer's patch. The section of appendix had histopathological signs of acute appendicitis. The patient was seen at follow-up in the outpatient department with marked improvement in his general health.

\section{Discussion}

Brucellosis, also known as 'undulant fever', is the most common zoonosis worldwide and an important public health problem in many developing countries [2]. Endemic areas for brucellosis include the Middle East, Central Asia, China, the Indian subcontinent, and Africa [3]. This bacterium is transmitted from animals to humans by ingestion of infected food products, direct contact with an animal, or inhalation of aerosols. Brucella species are aerobic gram-negative coccobacilli that possess a unique ability to invade both phagocytic and nonphagocytic cells and to survive in an intracellular environment by finding ways to avoid the immune system. This ability explains why brucellosis is a systemic disease and can involve almost every organ system [4].

Brucellosis may lead to a variety of clinical presentations. Fever and arthralgia of the large joints are the most common manifestations, followed by cough, malaise, myalgia, sweating, rash, and cardiac involvement. Being a systemic infection, it has multiple systemic manifestations. Although rare, gastrointestinal manifestations are diverse ranging from relatively milder complaints, such as anorexia, diarrhea, or constipation to more serious complications that have been reported in different case reports. It may present as an acute abdomen mimicking acute appendicitis, ileitis, infective colitis, acute cholecystitis, acute pancreatitis, mesenteric lymphadenitis, and intestinal obstruction [1,5-9].

Mesenteric lymphadenitis or inflammation and ulceration of Peyer's patches have been suggested as the possible mechanisms of Brucella-associated ileocolitis leading to perforation [1]. 
The clinical diagnosis of brucellosis can be difficult because of its nonspecific signs and symptoms so a high index of suspicion can lead to the correct diagnosis. It is important to get a detailed history which includes recent exposure to common host species of Brucella, especially cattle, sheep, goats, pigs, camels, buffaloes, or dogs; consumption of raw or inadequately cooked milk or milk products, meat, and offal derived from these animals. Occupational exposure, travel, or residence in an area in which the infection is prevalent also raises the probability of the diagnosis. The diagnosis is made with certainty when Brucella is recovered from the blood, bone marrow, or other tissues. Serological testing is the most commonly used method of diagnosing brucellosis among which the standard agglutination test is considered positive at titers of 1/160 or higher in case of active infection [5]. The Brucella ELISA is the most sensitive and specific serologic assay, and it may be positive when other tests are negative. Recently, polymerase chain reaction (PCR) has been developed for the detection of Brucella species in human blood specimens. A PCR test for samples other than blood has also been described [10]. Different tests can be joined to improve diagnostic yield [11]. A combination of PCR ELISA testing appears to be a highly sensitive and specific method for diagnosis [5].

The principle of the treatment of all forms of human brucellosis is the administration of effective antibiotics for an adequate length of time. The treatment option for the majority of brucellosis cases in adults and children (eight years of age and older) is doxycycline $100 \mathrm{mg}$ twice a day for six weeks with streptomycin $1 \mathrm{~g}$ daily for two to three weeks or doxycycline $100 \mathrm{mg}$ twice a day for six weeks with rifampicin 600-900 mg daily for six weeks $[12,13]$.

\section{Conclusions}

Brucellosis is an infection with multiple presentations. Therefore, clinical suspicion is required in cases presenting in endemic regions, especially when there is a history of exposure to animals and their products. This rare case report emphasizes that brucellosis is a preventable and treatable condition that must be considered in the differential diagnosis of acute abdomen and fever.

\section{Additional Information \\ Disclosures}

Human subjects: Consent was obtained by all participants in this study. Conflicts of interest: In compliance with the ICMJE uniform disclosure form, all authors declare the following: Payment/services info: All authors have declared that no financial support was received from any organization for the submitted work. Financial relationships: All authors have declared that they have no financial relationships at present or within the previous three years with any organizations that might have an interest in the submitted work. Other relationships: All authors have declared that there are no other relationships or activities that could appear to have influenced the submitted work.

\section{Acknowledgements}

We are grateful to Dr. Rai Amir Wazir and Dr. Asim Shahzad from Benazir Bhutto Hospital Surgical Unit II, Rawalpindi, Pakistan for helping us in writing this case report.

\section{References}

1. Mazokopakis EE, Giannakopoulos TG, Christias EG: Acute brucellosis as a cause of infective colitis . Mil Med. 2008, 173:1145-1147. 10.7205/milmed.173.11.1145

2. Pappas G, Akritidis N, Bosilkovski M, Tsianos E: Brucellosis. N Engl J Med. 2005, 352:2325-2336. 10.1056/NEJMra050570

3. Pappas G, Papadimitriou P, Akritidis N, Christou L, Tsianos EV: The new global map of human brucellosis . Lancet Infect Dis. 2006, 6:91-99. 10.1016/S1473-3099(06)70382-6

4. Brucellosis. (2018). Accessed: November 29, 2019: https://emedicine.medscape.com/article/213430overview.

5. Papaioannides D, Korantzopoulos P, Sinapidis D, Charalabopoulos K, Akritidis N: Acute pancreatitis associated with brucellosis. J Pancreas. 2006, 7:62-65.

6. Fernández MD, García JLZ, García FD, Fernández MTC: Brucella acute abdomen mimicking appendicitis . Am J Med. 2000, 108:599-600. 10.1016/S0002-9343(00)00299-0

7. Petrella R, Young EJ: Acute brucella ileitis. Am J Gastroenterol. 1988, 83:80-82.

8. Fasquelle D, Charignon G, Rami M: Acute calcular cholecystitis in a patient with brucellosis . Eur J Clin Microbiol Infect Dis. 1999, 18:599-600. 10.1007/s100960050355

9. Aziz S, Al-Anazi AR, Al-Aska AI: A review of gastrointestinal manifestations of brucellosis . Saudi J Gastroenterol. 2005, 11:20-27. 10.4103/1319-3767.33333

10. Morata P, Queipo-Ortuno MI, Reguera JM, Miralles F, Lopez-Gonzalez JJ, Colmenero JD: Diagnostic yield of a PCR Assay in focal complications of brucellosis. J Clin Microbiol. 2001, 39:3743-3746. 10.1128/JCM.39.10.3743-3746.2001

11. Akhvlediani T, Bautista CT, Garuchava N, et al.: Epidemiological and clinical features of brucellosis in the country of Georgia. PLoS One. 2017, 12:e0170376. 10.1371/journal.pone.0170376

12. Ariza J, Bosilkovski M, Cascio A, et al.: Perspectives for the treatment of brucellosis in the 21st century: the Ioannina recommendations. PLoS Med. 2007, 4:e317. 10.1371/journal.pmed.0040317

13. Joint FAO/WHO expert committee on brucellosis: sixth report . World Health Organ Tech Rep Ser. 1986, 740:1-132. 